\title{
Papillary cystoadenoma lymphomatosum (Warthin-like) of minor salivary glands
}

\author{
Laura Párraga-Linares ${ }^{1}$, Jose-María Aguirre-Urízar ${ }^{2}$, Leonardo Berini-Aytés ${ }^{3}$, Cosme Gay-Escoda ${ }^{4}$
}

${ }^{1}$ DDS. Resident of the Master of Oral Surgery and Implantology. Barcelona University Dental School. Barcelona (Spain) ${ }^{2}$ MD; DDS; PhD. Chairman of Oral Medicine. Specialist Doctor in Pathological Anatomy. Basque Country University Dental School. Leioa (Spain)

${ }^{3}$ MD; DDS; PhD. Professor, Department of Oral and Maxillofacial Surgery, and Professor of the Master of Oral Surgery and Implantology. Dean of the University of Barcelona Dental School. Barcelona (Spain). UB- IDIBELL Research Group

${ }^{4} \mathrm{MD}$; DDS; PhD. Chairman of Oral and Maxillofacial Surgery. Director of the Master of Oral Surgery and Implantology. Barcelona University Dental School. Director of the Service of Oral and Maxillofacial Surgery, Teknon Medical Center. Barcelona (Spain). UB- IDIBELL Research Group

Correspondence:

Centro Médico Teknon

Instituto de investigación

UB-IDIBELL

C/Vilana, 12

08022. Barcelona

cgay@ub.edu

Received: $21 / 11 / 2008$ Accepted: 20/05/2009
Párraga-Linares L, Aguirre-Urízar JM, Berini-Aytés L, Gay-Escoda C. Papillary cystoadenoma lymphomatosum (Warthin-like) of minor salivary glands. Med Oral Patol Oral Cir Bucal. 2009 Nov 1;14 (11):e597600 .

http://www.medicinaoral.com/medoralfree01/v14i11/medoralv14i11p597.pdf

\begin{tabular}{|l|}
\hline Article Number: $2571 \quad$ http://www.medicinaoral.com/ \\
C) Medicina Oral S. L. C.I.F. B 96689336-pISSN 1698-4447 - eISSN: 1698-6946 \\
eMail: medicina@medicinaoral.com \\
Indexed in: \\
-SCI EXPANDED \\
-JOURNAL CITATION REPORTS \\
-Index Medicus / MEDLINE / PubMed \\
-EMBASE, Excerpta Medica \\
-SCOPUS \\
-Indice Médico Español
\end{tabular}

\begin{abstract}
Papillary cystadenoma lymphomatosum is a benign salivary gland tumor most frequently located in the parotid gland (Warthin's tumor). Its presentation in other major, or in minor, salivary glands is rare. Clinically, it manifests as a slow growing tumor, fluctuant on palpation due to its cystic morphology. The treatment of choice is complete excision with wide tumor-free margins. We present a 73-year-old female patient with an asymptomatic tumor of 8 years evolution in the right posterior area of the hard palate. We performed surgical excision and a biopsy, which was reported as papillary cystadenoma lymphomatosum. During the post-operative examination carried out after 3 weeks, it was observed that the lesion had recurred. The lesion was re-operated, performing the excision with $\mathrm{CO}_{2}$ laser and including the periosteum to ensure complete resection of the tumor. At 10 months follow-up, there was no recurrence of the lesion. This article includes a review of this condition and discusses its most important clinical and pathologic features and therapeutic approaches.
\end{abstract}

Key words: Papillary cystadenoma lymphomatosum, tumor of the parotid gland, tumor of the minor salivary gland, Warthin's tumor. 


\section{Introduction}

Papillary cystadenoma lymphomatosum (PCL) was first described in 1929 by Warthin, receiving since then the name of Warthin's tumor (WT) when present in the parotid gland. It is a benign salivary gland tumor most frequently located in the parotid gland, its presentation in other major or minor salivary glands is extremely rare. It is a well defined entity, with a dual histological component, oncocytic epithelium and a lymphoid stroma (1). It is believed that this lesion stems from ductal elements trapped and developing within the parotid lymph nodes, suggesting that the adenomatous cystic proliferation triggers a secondary lymphoid reactive response in the stroma (2-4). WT is the second most frequent benign tumor of the salivary glands after pleomorphic adenoma, representing between $10 \%$ and $15 \%$ of the total $(3,4)$. Over $80 \%$ of the cases are located in the superficial lobe of the parotid gland in close relation to the lymph nodes (2). Clinically, it manifests as a slow growing tumor, fluctuant on palpation due to its cystic structure, and about $10 \%$ of cases are bilateral. The treatment of choice for WT is surgical resection with tumor free margins, including an intraoperative histological study, always confirmed by posterior pathological analysis $(1,3,5)$.

Malignant cases of this neoplasm have been reported, originating from both the lymphoid and the epithelial component, as well as the appearance of a leukemia or a metastatic melanoma in the lymphoid component of the tumor $(6,7)$. The purpose of this article is to present a case of papillary cystadenoma lymphomatosum (Warthin-like) in a very unusual location and to analyze and discuss the main clinical and pathological features of this lesion.

\section{Case Report}

A 73-year-old, female, Caucasian patient, allergic to penicillin and with a medical history of hypertension, depression and hypercholesterolemia for which she is treated pharmacologically with Simvastatin (Tarbis ${ }^{\circledR}$, Belmac, Zaragoza, Spain) $20 \mathrm{mg} / 1$ tablet a day, Lormetazepan (Noctamid ${ }^{\circledR}$, Shering, Lyz-Lez-Lannoy, France) $2 \mathrm{mg}$ / 1 tablet a day, Captopril (Cinfa ${ }^{\circledR}$, Cinfa, Pamplona, Spain) $25 \mathrm{mg} / 1 / 2$ tablet a day, Domperidona (Montilium 巴), Dr.Esteve, Barcelona, Spain) $10 \mathrm{mg} / 1$ tablet a day, sertraline hydrochloride (Besitran ${ }^{\circledR}$, Pfízer, Barcelona, Spain) $50 \mathrm{mg} / 1$ tablet a day and Omeprazole (Cuve ${ }^{\circledR}$, Cuvefarma, Cordoba, Spain ) $20 \mathrm{mg} / 1$ tablet a day. She has no related toxic habits and had been operated for a facial sebaceous cyst and two Caesarean sections.

She attended the Oral Surgery Service at the Dental Clinic of the University of Barcelona presenting a painless tumor of 8 years evolution, on the right posterior part of the hard palate (Figure 1). The patient had been wearing upper and lower removable partial dentures for 20 years. After referring irritation caused by trauma of the prosthesis on the lesion 3 months earlier the pros- thesis had been adjusted, releasing the palate. The tumor persisted so the patient was referred to our department for diagnosis and treatment.

Examination revealed an erythematous tumor, $6 \mathrm{~mm}$ in diameter, multinodular on the surface, non-ulcerated and painless. A possible odontogenic origin was ruled out by a dental and intraoral radiographic examination. Computed tomography showed no bone alterations in the area of the lesion.

All these data led to a presumptive diagnosis of benign salivary tumor (pleomorphic adenoma). An excisional biopsy of the lesion was performed under local anesthesia with surgical scalpel (Figure 2), removing the entire

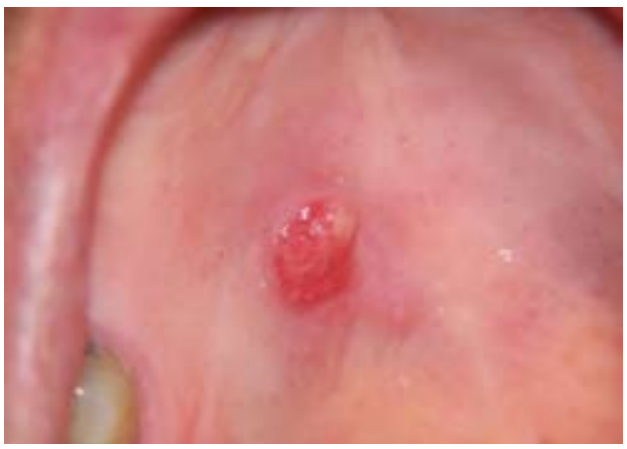

Fig. 1. Initial palatal swelling, of erythematous, nodular appearance.

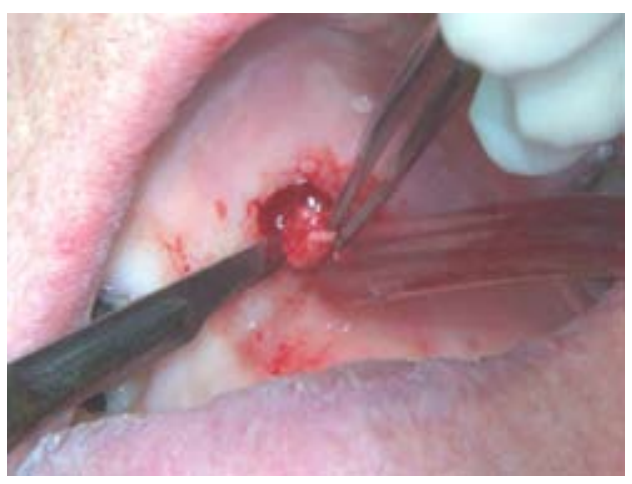

Fig. 2. Treatment of the lesion. Excisional biopsy excisional with scalpel under local infiltrative anesthesia.

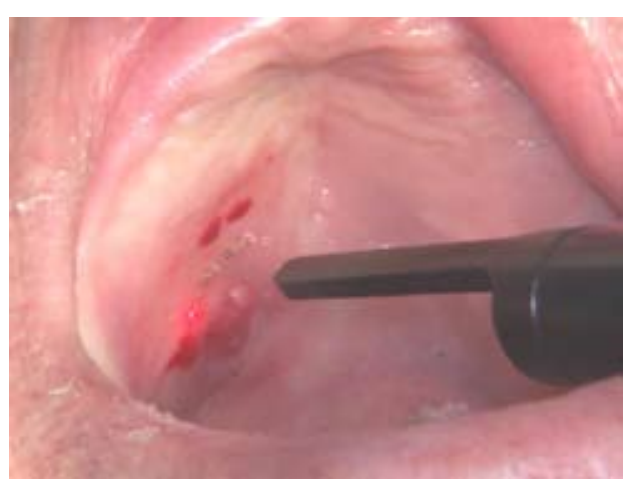

Fig. 3. Surgical reoperation. Excision of the lesion with $\mathrm{CO}_{2}$ laser. 
tumor with tumor free margins but not including the periosteum. We placed an $\mathrm{X}$ suture which held a textured collagen dressing Lyostyp ${ }^{\circledR}$ (Braun Aesculap AG, Tuttlingen, Germany) to promote hemostasis. The wound healed by secondary intention and there were no intraoperative or postoperative complications.

The histopathological examination revealed a papillary cystadenoma lymphomatosum (Warthin-like) with cystic spaces lined by a papillary epithelial proliferation with a double layer of columnar eosinophilic cells. At the core of the papillary projections a variable amount of lymphoid tissue with mature lymphocytes was observed.

At the 3 weeks control it was found that the lesion had recurred, noticing again an asymptomatic erythematous tumor, $5 \mathrm{~mm}$ in diameter, and with clinical characteristics identical to the original, so it was decided to reoperate. On this occasion $\mathrm{CO}_{2}$ laser was used to resect the lesion including the periosteum to ensure a complete excision (Figure 3). The result of this second biopsy was again PCL. At one month follow-up it was noted that the surgical wound had healed without complications.

The monitoring protocol includes regular checks every 6 months during the first year and every year thereafter. Currently, after 10 months of follow-up, there is no evidence of recurrence of the lesion.

\section{Discussion}

PCL is a tumor almost exclusively of the parotid gland, its appearance in other salivary glands is very rare and controversial (3). Its possible origin is discussed by several authors $(2-4,8)$, including Thompson and Bryant (8), who see it as a true neoplastic proliferation of the channels of the salivary glands, while others (3) believe it has a reactive or metaplastic origin.

The first case of PCL located in minor salivary glands was described in 1954, with very few cases published in the literature since then $(1,5,9)$. In the review published by Eveson and Cawson (3) in 1986 of 278 cases of WT, only 2 appeared in the submaxillary gland, and the most common location was the parotid gland with $99.2 \%$ of the cases. Toida et al. (10) in a clinicopathologic study of 82 cases of tumors of the minor salivary glands found no case of PCL. Similarly, Jaber (11) in a series of 75 cases of tumors of the minor salivary glands found 26 located in the hard palate (34.6\%) but no case corresponded to a PCL. Yih et al. (12) also published a retrospective study of 213 cases of minor salivary gland tumors, with 91 cases $(42.72 \%)$ located in the palate of which none was a PCL. In both studies $(11,12)$ pleomorphic adenoma was the most frequent benign tumor, and mucoepidermoid carcinoma the most frequently diagnosed malignant tumor.

WT appears in adults, presenting the highest incidence between the ages of 58 and 70 years $(3,5)$. Regarding sex, for some authors the ratio between men and women is similar, 1.6:1 (3), although in this respect there is much controversy, as other authors $(2,5)$ find a predominance of males versus females with a ratio of 5:1.

The most common location of PCL is the parotid gland, although some cases have been described in the buccal mucosa (1), submaxillary gland (3), lip and palate $(1,5)$. In a large series (3), $99.2 \%$ of WT were located in the parotid gland and only $0.8 \%$ in the submaxillary gland. The World Health Organization classifies WT within benign epithelial tumors. Macroscopically WT presents as a spherical or ovoid mass, with a dense fibrous capsule and displaying multiple cystic compartments filled with a viscous yellow or dull brown material. However, Eveson and Cawson (5) found $77 \%$ of cases with an incomplete capsule, a full capsule in $8 \%$ and $16 \%$ of tumors in which there was no evidence of capsule.

Microscopically it is a well-circumscribed tumor, typically cystic and papillary, with an adenoid columnar eosinophilic oncocytic epithelial lining arranged in two layers resting on a background of lymphoid stroma. Electron microscopy confirms the massive accumulation of mitochondria in the cytoplasm of oxyphilic epithelial cells, as well as the presence of crystalloid structures within them. Immunohistochemistry has shown that most of these are B lymphocytes, 50\% contain IgG, 33\% $\operatorname{IgA}$ and the rest $\operatorname{IgM}, \operatorname{IgD}$ and $\operatorname{IgE}(13)$. In regard to the relative amounts of lymphoid and epithelial components, several distinct subtypes of WT have been distinguished, pointing to an evolution in tumor progression based on the increase in the lymphoid component (2).

Some authors (2) consider WT to be an adenomatous epithelial proliferation that promotes a secondary lymphoid reaction mediated by intratumoral immunological phenomena.

Some malignant cases have been reported, in relation to both the epithelial and the lymphoid component, as well as the appearance of a leukemia or metastasis in the latter (6). Skalova et al. (7) presented a case of a squamous cell carcinoma derived from a PCL located in the parotid gland of an 80-year-old woman.

Clinically, the WT usually presents as a slow growing tumor, cases of to 20 years evolution having been published (3). Our case with an 8-year evolution would be within these evolutionary parameters. Palpation of the tumor is often fluctuant given its cystic composition, and can vary in size from a few millimeters to centimeters. Accordingly, in the series of Eveson and Cawson (3), 56\% of the tumors measured between 1 and $3 \mathrm{~cm}, 40 \%$ from 4 to $6 \mathrm{~cm}$ and only one exceeded $10 \mathrm{~cm}$ in diameter.

The differential diagnosis of this malignancy should be performed preferably with pleomorphic adenoma and cystoadenoma (14). The anatomicopathological diagnosis is generally easy, but it also should be distinguished from canalicular adenoma, sialadenoma as well as from branchial cyst when involving the parotid gland. 
A scintigram with the radioisotope Technetium 99m pertechnetate is often helpful in the diagnosis of parotid tumors because the WT captures the isotope and behaves like a hot spot.

The treatment of choice for these tumors is local excision with a wide tumor free margin to prevent potential recurrence. It is important to bear in mind that when located in the parotid gland between 5 and $10 \%$ can be bilateral and 10 to $15 \%$ multicentric. In the series published by Eveson and Cawson (3), 30 were bilateral (5\%), 3 cases (1\%) recurred after one, 3 and 7 years, respectively.

We can conclude that PCL is a benign salivary gland tumor; very rarely occurring in the minor salivary glands. The treatment of choice is surgical excision with tumor free margins to prevent recurrence and / or possible malignant transformation of this tumor. The possibility of recurrence in salivary tumors requires scheduling regular checks every 6 months for at least 10 years.

\section{References}

1. Fantasia JE, Miller AS. Papillary cystadenoma lymphomatosum arising in minor salivary glands. Oral Surg Oral Med Oral Pathol. 1981;52:411-6.

2. Aguirre JM, Echebarría MA, Martínez-Conde R, Rodriguez C, Burgos JJ, Rivera JM. Warthin tumor. A new hypothesis concerning its development. Oral Surg Oral Med Oral Pathol Oral Radiol Endod. 1998;85:60-3.

3. Eveson JW, Cawson RA. Warthin's tumor (cystadenolymphoma) of salivary glands. A clinicopathologic investigation of 278 cases. Oral Surg Oral Med Oral Pathol. 1986;61:256-62.

4. Seifert G, Bull HG, Donath K. Histologic subclassification of the cystadenolymphoma of the parotid gland. Analysis of 275 cases. Virchows Arch A Patho Anat Histol. 1980;388:13-38.

5. Baden E, Pierce M, Selman AJ, Roberts TW, Doyle JL. Intraoral papillary cystadenoma lymphomatosum. J Oral Surg. 1976;34:53341.

6. Dardick I, Claude A, Parks WR, Hoppe D, Stinson J, Burns BF, et al. Warthin's tumor: an ultrastructural and immunohistochemical study of basilar epithelium. Ultrastruct Pathol. 1988;12:419-32.

7. Skálová A, Michal M, Nathanský Z. Epidermoid carcinoma arising in Warthin's tumour: a case study. J Oral Pathol Med. 1994;23:330-3. 8. Thompson AS, Bryant HC Jr. Histogenesis of papillary cystadenoma lymphomatosum (Warthin's tumor) of the parotid salivary gland. Am J Pathol. 1950;26:807-49.

9. Hendrick JW. Papillary cystadenoma lymphomatosum of the palate. Report of a case. Arch Otolaryngol. 1964;79:15-7.

10. Toida M, Shimokawa K, Makita H, Kato K, Kobayashi A, Kusunoki $\mathrm{Y}$, et al. Intraoral minor salivary gland tumors: a clinicopathological study of 82 cases. Int J Oral Maxillofac Surg. 2005;34:528-32.

11. Jaber MA. Intraoral minor salivary gland tumors: a review of 75 cases in a Libyan population. Int J Oral Maxillofac Surg. 2006;35:150-4. 12. Yih WY, Kratochvil FJ, Stewart JC. Intraoral minor salivary gland neoplasms: review of 213 cases. J Oral Maxillofac Surg. 2005;63:80510.

13. Korsrud FR, Brandtzaeg P. Immunohistochemical characterization of cellular immunoglobulins and epithelial marker antigens in Warthin's tumor. Hum Pathol. 1984;15:361-7.

14. Gallego L, Junquera L, Fresno MF, De Vicente JC. Papillary cystadenoma and cystadenocarcinoma of salivary glands: two unusual entities. Med Oral Patol Oral Cir Bucal. 2008;13:E460-3. 